\title{
O EFEITO IMUNOMODULADOR DA MICROBIOTA INTESTINAL, AS CONSEQUÊNCIAS DE SEU DESEQUILÍBRIO E A PROFILAXIA PROBIÓTICA
}

\author{
THE IMMUNOMODULATORY EFFECT OF THE INTESTINAL MICROBIOTA, THE \\ CONSEQUENCES OF ITS IMBALANCE AND PROBIOTIC PROPHYLAXIS
}

\author{
Greik Machado Franca ${ }^{1}$ \\ Gilberto Saldanha da Cruz ${ }^{2}$ \\ Renato Pissinati Morais ${ }^{3}$ \\ Alanna Kerlen Costa Dias ${ }^{4}$ \\ Maria Eloisa da Silva Araujo ${ }^{5}$ \\ Lívia Martins Moreira ${ }^{6}$ \\ André Luiz Faleiro Soares ${ }^{7}$
}

RESUMO: O intestino, há tempos, passou a ser estudado não apenas como um dos órgãos do sistema digestivo, mas também como peça fundamental na resposta imunológica. Ele abriga grande parte do tecido linfoide do ser humano. $O$ tecido linfoide associado ao intestino é responsável por reconhecer agentes patogênicos e promover a devida resposta imune. Além do tecido linfoide, o intestino possui em sua mucosa uma grande diversidade de microrganismos, vivendo em simbiose com o ser humano. $O$ conjunto de microrganismos é conhecido como microbiota intestinal e desempenha um papel fundamental na nutrição, na proteção e na homeostase intestinal. O desequilíbrio da microbiota intestinal, disbiose, vem sendo estudado como um dos principais fatores que possibilitam o desenvolvimento de diversas patologias intestinais e extra intestinais. A saúde da microbiota intestinal reflete diretamente na saúde do hospedeiro. Este trabalho é uma pesquisa exploratória baseada na revisão bibliográfica de artigos publicados do ano de 1995 a 2016 com o objetivo de demonstrar a importância de se manter a microbiota saudável, evidenciando seus mecanismos de atuação, além de descrever a sua ação imunomoduladora e os problemas decorrentes de seu desequilíbrio. Por fim, descrevendo a eficácia da utilização dos probióticos e simbióticos no tratamento e prevenção de doenças intestinais.

\footnotetext{
${ }^{2}$ Greik Machado Franca. Discente do curso de Biomedicina da Faculdade Única de Ipatinga (FUNIP). Email: greik_ferrari@hotmail.com

${ }_{2}^{2}$ Gilberto Saldanha da Cruz. Discente do curso de Biomedicina da Faculdade Única de Ipatinga (FUNIP). Email: saldanhacruz@hotmail.com

${ }^{3}$ Renato Pissinati Morais. Discente do curso de Biomedicina da Faculdade Única de Ipatinga (FUNIP). Email: renatopissinati@hotmail.com

${ }^{4}$ Alanna Kerlen Costa Dias. Discente do curso de Biomedicina da Faculdade Única de Ipatinga (FUNIP). Email: alannakerlen@yahoo.com.br

5 Maria Eloisa da Silva Araujo. Discente do curso de Biomedicina da Faculdade Única de Ipatinga (FUNIP). Email: mariar23186@outlook.com

${ }^{6}$ Lívia Martins Moreira. Discente do curso de Biomedicina da Faculdade Única de Ipatinga (FUNIP). Email: limamoreira@live.com

7 Docente da Faculdade Única de Ipatinga (FUNIP).
} 
Palavras-chave: Microbiota intestinal. Flora intestinal. Probióticos. Sistema imune.

ABSTRACT: The intestine has long been studied not only as one of the organs of the digestive system, but also as a keystone in the immune response. It harbors much of the lymphoid tissue of the human being. The lymphoid tissue associated with the intestine is responsible for recognizing pathogens and promoting the proper immune response. Besides the lymphoid tissue, the intestine has in its mucosa a great diversity of microorganisms, living in symbiosis with the human being. The set of microorganisms is known as intestinal microbiota and plays a key role in nutrition, protection and intestinal homeostasis. The imbalance of the intestinal microbiota, dysbiosis, has been studied as one of the main factors that allow the development of various intestinal and extra intestinal pathologies. The health of the intestinal microbiota directly reflects on the health of the host. This work is an exploratory research based on the bibliographical review of published articles from the year I995 to 2016 with the objective of demonstrating the importance of keeping the microbiota healthy, showing its mechanisms of action, as well as describing its immunomodulatory action and the resulting problems of their imbalance. Finally, describing the effectiveness of the use of probiotics and symbiotics in the treatment and prevention of intestinal diseases.

Keywords: Intestinal microbiota. Intestinal flora. Probiotics. Immune system.

INTRODUÇÃO

A microbiota intestinal é composta por diversos microrganismos, estimando-se por volta de 400 a 1000 espécies diferentes. Importantes para as funções metabólicas do organismo, estes microrganismos são capazes de aproveitar a energia contida nos elementos da dieta que não são metabolizados pelo organismo humano e que seriam excretados. A microbiota humana é constituída tanto por bactérias benéficas, que exercem papeis fundamentais na proteção e nutrição da parede do intestino, quanto por bactérias com elevado potencial patogênico, além de fungos e leveduras. Estes microrganismos colonizadores são classificados respectivamente como microbiota natural, transitória ou patogênica (PAIXÃO; CASTRO, 2016).

Além de amplificar as funções nutricionais do intestino, a microbiota natural desempenha um papel essencial no que tange à defesa do organismo humano como um todo, pois funciona como um agente regulador do desencadeamento da resposta imune. Tal regulação, gerada pela microbiota comensal, na qual se destacam os lactobacilos, as bifidobactérias e as eubactérias, tem efeito direto na resistência à colonização por patógenos 
e na produção de diversas substâncias que reforçam a atividade imunitária (LEVINSON, 2010).

A disbiose, desequilíbrio da microbiota intestinal, pode ser causada por diversos fatores como nutrição inadequada e uso de medicamentos. Por não estar catalogada como doença na Classificação Internacional de Doenças (CID-ıo), não há disponibilidade de dados epidemiológicos referentes à disbiose especificamente, somente de seus sinais e sintomas que, a princípio, podem ser considerados de outras doenças. As patologias consequentes da disbiose são várias e afetam diretamente os intestinos ocasionando uma cascata de efeitos sistêmicos deletérios para o individuo e, por vezes, fatais.

Os probióticos são suplementos alimentares constituídos por microrganismos vivos e em quantidade adequada, cujo objetivo é a promoção do equilíbrio da microbiota intestinal, proporcionando benefícios ao hospedeiro (FLESH; POZIOMYCK; DAMIM, 2014). Segundo Sturmer et al. (2012), diversos são os benefícios da ingestão dos probióticos, dentre eles o estímulo da motilidade intestinal e absorção de nutrientes, controle de infecções intestinais e estímulo do sistema imunológico.

Justifica-se o interesse por esta pesquisa, a preocupação pela falta de notificação quanto à incidência da disbiose, sua gravidade e letalidade. Atualmente a prática clínica adotada no tratamento das doenças oriundas da disbiose se faz pelo uso de probióticos ou, como em alguns países, pelo transplante da microbiota, denominado de transplante fecal, no tratamento de infecção por Clostridium difficile. Faz-se necessário estudo sobre a aplicação de uma forma de tratamento profilático, evitando assim desconfortos desagradáveis.

Apesar dos mecanismos pelos quais as bactérias intestinais estimulam o sistema imunológico não serem completamente elucidados, acredita-se na ação da microbiota no intestino para o fortalecimento do sistema imunológico através do estímulo à produção de anticorpos, ativação de macrófagos e proliferação de linfócitos T (CARVALHO; SOARES; SOARES, 2012)

Espera-se ao final deste trabalho demonstrar a importância da microbiota intestinal, assim como sua relação com o sistema imunológico, seus efeitos gerados pela interrupção da homeostasia e a ação profilática dos probióticos e simbióticos. 


\section{OBJETIVOS}

\section{I Objetivo Geral}

Descrever a importância da microbiota intestinal, sua relação com o sistema imunológico, os efeitos de seu desequilíbrio e a ação profilática dos probióticos.

\subsection{Objetivos Específicos}

Descrever a formação e composição da microbiota intestinal;

Descrever seus mecanismos da atuação;

Descrever os mecanismos que promovem a interação entre intestino e a ativação da resposta imune;

Evidenciar as causas e consequências de eventuais disbioses;

Descrever os principais probióticos utilizados na recolonização comensal no intestino.

\section{METODOLOGIA}

O trabalho proposto trata-se de uma pesquisa exploratória de revisão de literatura especializada sobre a microbiota intestinal, suas funções e a ação profilática dos probióticos. Realizada através da busca de artigos científicos em bases de dados bibliográficos durante os meses de agosto a novembro de 2018. As bases utilizadas para as buscas foram Lilacs (Literatura Latino-americana e do Caribe em Ciências da Saúde), Pubmed/Medline (Medical Literature Analisysand Retrieval System Online) e Scielo (Scientific Eletronic Library Online), utilizando as seguintes palavras-chave: disbiose, probióticos, sistema imune, Lactobacillus sp., Bifidobacterium sp.. Foram priorizados artigos publicados a partir de 2012, e dando atenção necessária àqueles publicados antes desta data com relevância científica, nas línguas inglesa, portuguesa e espanhola. 


\section{DESENVOLVIMENTO \\ 3.1 O Intestino e Microbiota Intestinal}

Há muito o intestino vem sendo estudado, não apenas como aparelho de digestão, absorção e excreção de alimentos. Além dessas funções, existe uma grande quantidade de tecido linfático associado ao intestino (GALT), o que lhe confere uma participação ativa e fundamental no processo de reconhecimento de patógenos, comunicação e ativação do sistema imunológico. Anatomicamente, o GALT pode ser visto na forma de nódulos linfáticos isolados e distribuídos ao longo do epitélio intestinal ou formando agregados linfoides na porção mais distal do íleo, clinicamente denominados Placas de Peyer (PP) (FIGURA I). Esses tecidos linfoides possuem uma grande quantidade de proteínas de reconhecimento dos padrões de patógenos e células "M" (micro dobras) (ASHIDA et al., 2012).

FIGURA I - Morfologia do Intestino.

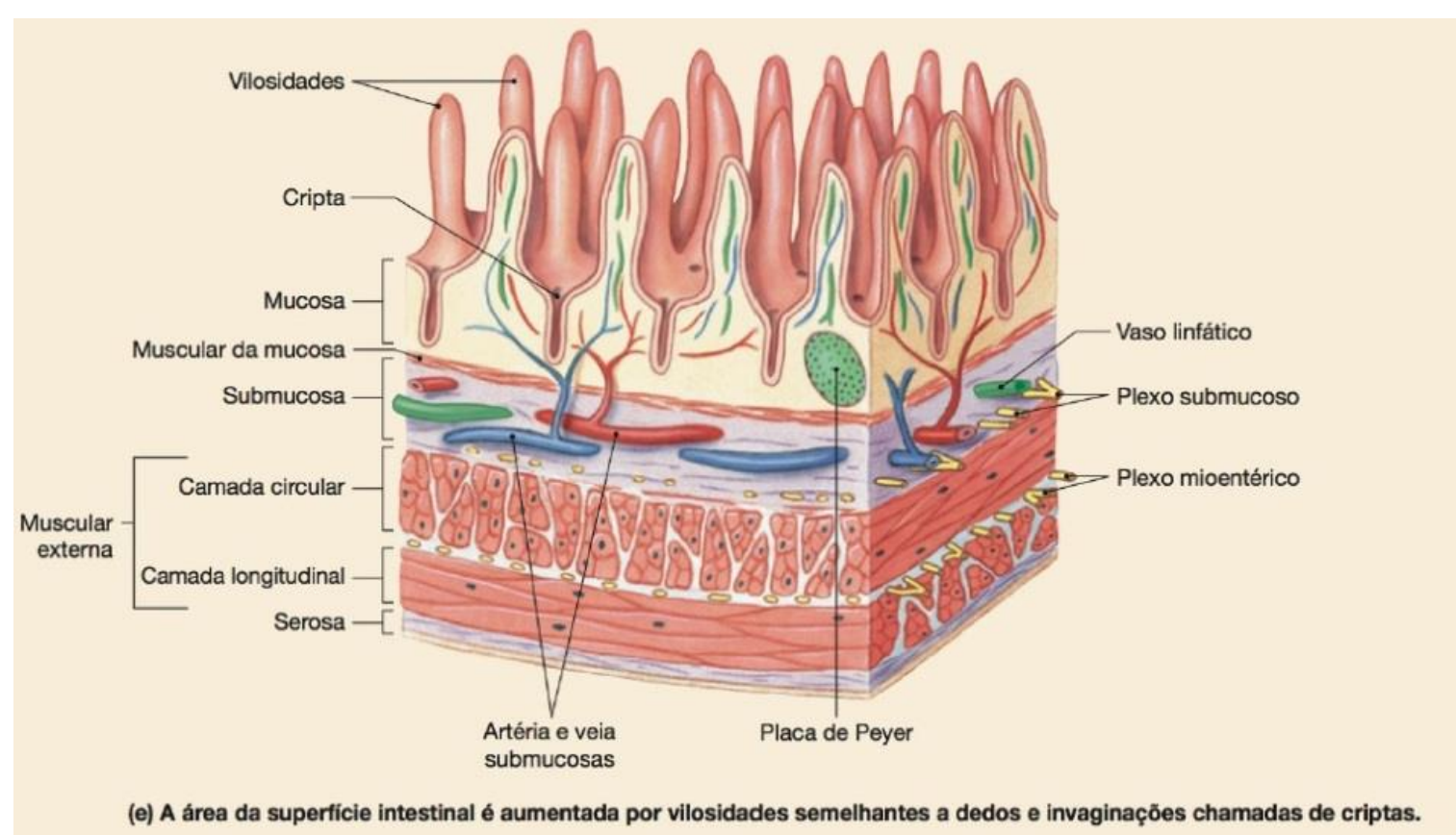

Fonte: https://resumosdemedicina.wordpress.com/2016/o4/II/anatomia-do-sistemadigestorio 
As células $\mathrm{M}$ são células associadas aos linfonodos e as $\mathrm{PP}$, responsáveis pelo reconhecimento e absorção de antígenos, células mortas e nutrientes presentes no intestino. A ação das células $M$ facilita a transmissão de informações sobre presença destes antígenos no lúmen intestinal para o tecido linfoide, favorecendo a ativação da resposta imune mediada pelos macrófagos, células dendríticas e linfócitos $\mathrm{T}$, amplamente distribuídos no tecido linfoide subepitelial conhecido como lâmina própria (FIGURA 2) (VOLMAN; RAMAKERS;PLAT, 2008).

FIGURA 2 - Ação das Células M.

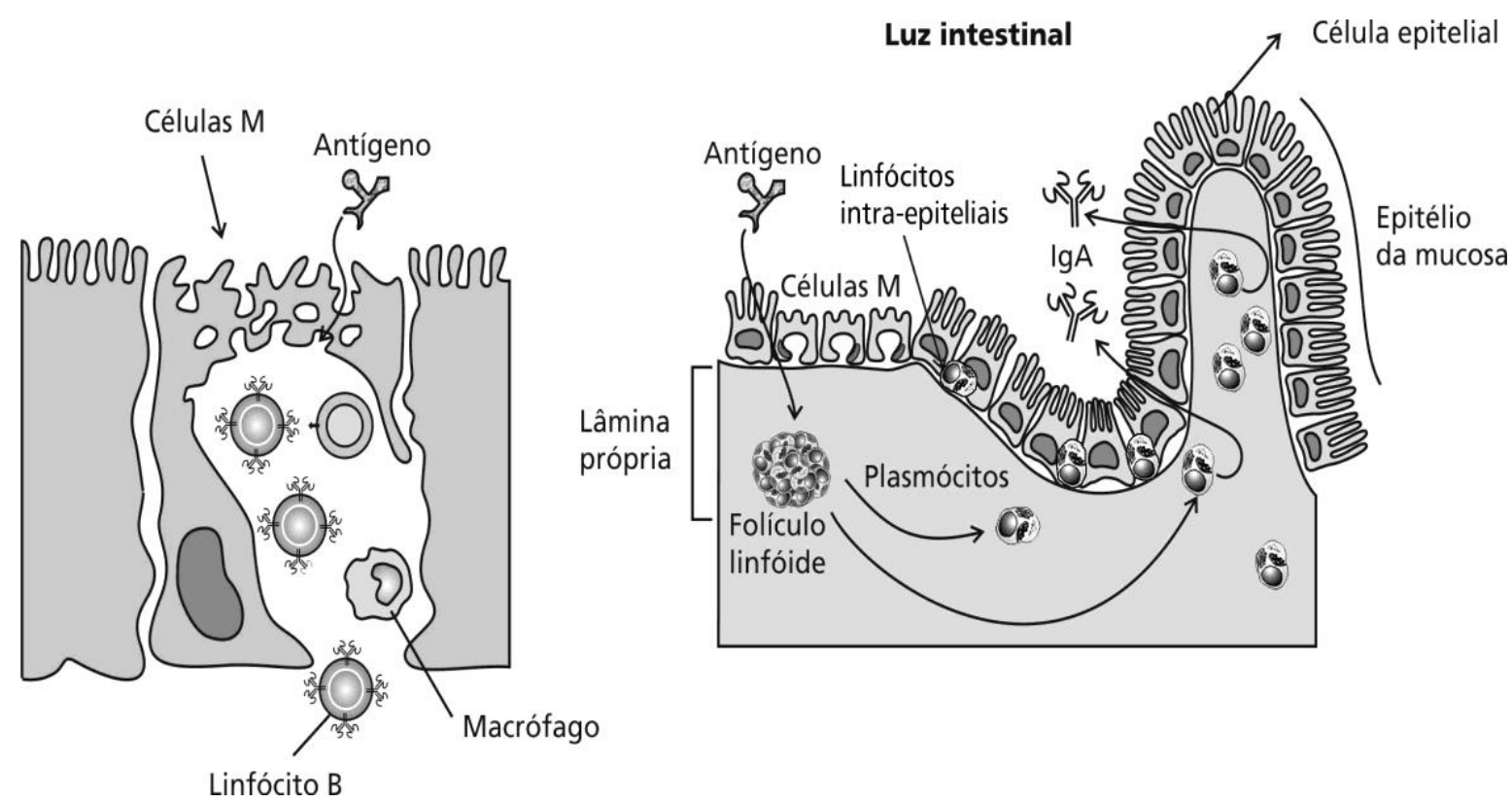

Fonte: https://canalcederj.cecierj.edu.br/recurso/8328

A parede intestinal é formada por diversas camadas de diferentes tecidos. Sobre essas camadas, mais especificamente as vilosidades, existe uma população natural de bactérias, fungos e leveduras que, por simbiose, assumem um papel essencial no metabolismo de substâncias, além da nutrição e proteção da parede intestinal. Esse conjunto de microrganismos é conhecido como microbiota intestinal (CARICILLI et al., 20II).

Esta microbiota, composta por cerca de Ioo trilhões de microrganismos de até I.ooo espécies diferentes, protege o organismo contra infecções, bloqueia a colonização do intestino por bactérias patogênicas, controla o $\mathrm{pH}$ (potencial iônico de hidrogênio) do meio 
e estimula o sistema imune (TABELA I). Essas bactérias que compõem a microbiota efetuam atividades enzimáticas que propiciam a digestão de alimentos, facilitam a absorção de nutrientes, principalmente íons, e atuam na produção de vitaminas (OLIVEIRA; BATISTA, 2016).

Os principais gêneros de bactérias benéficas intestinais são as Bifidobacterium sp., os Lactobacillus sp. e Bacteroides sp., sendo as duas primeiras, as principais bactérias utilizadas em composições probióticas para consumo oral. As bactérias do gênero Bifidobacterium sp. constituem a maior parte da microbiota intestinal de crianças e em número importante nos adultos (STURMER et al., 2012).

TABELA I - Distribuição dos microrganismos mais representativos no trato gastrointestinal em adultos saudáveis.

Gêneros bacterianos predominantes (unidades formadoras de colônias $/ \mathrm{mL}$ ou $/ \mathrm{g}$ )

\begin{tabular}{|c|c|c|}
\hline $\begin{array}{l}\text { Estômago e Duodeno } \\
10^{1}-10^{3}\end{array}$ & $\begin{array}{l}\text { Jejuno e íleo } \\
10^{4}-10^{8}\end{array}$ & $\begin{array}{l}\text { Cólon } \\
10^{10}-10^{12}\end{array}$ \\
\hline $\begin{array}{l}\text { Lactobacillus } \\
\text { Streptococcus } \\
\text { Levedura }\end{array}$ & $\begin{array}{l}\text { Lactobacillus } \\
\text { Enterobactérias } \\
\text { Streptococcus } \\
\text { Bacteroides } \\
\text { Bifidobacterium } \\
\text { Fusobacterium }\end{array}$ & $\begin{array}{l}\text { Bacteroides } \\
\text { Bifidobacterium } \\
\text { Streptococcus } \\
\text { Fusobacterium } \\
\text { Enterobactérias } \\
\text { Clostridium } \\
\text { Veillonella } \\
\text { Lactobacillus } \\
\text { Proteus } \\
\text { Staphylococcus } \\
\text { Pseudomonas } \\
\text { Leveduras } \\
\text { Protozoa }\end{array}$ \\
\hline
\end{tabular}

Fonte: Adaptado de MORAIS e JACOB (2006)

A microbiota humana primária pode sofrer diversas interferências negativas durante sua formação por fatores como o parto por cesariana, devido a esterilidade do procedimento; o aleitamento materno que quando evitado ou impossibilitado diminui a 
ingestão de anticorpos presentes no leite; e a exposição ambiental, que está ligada à infecção por patógenos (ANDRADE, 20I0).

O desenvolvimento e a instalação da microbiota natural estão diretamente ligados à formação da microbiota primária que, quando impossibilitada, diminui a proteção e nutrição da parede intestinal, aumentando a probabilidade da ocorrência de processos inflamatórios e irritativos, dificultando assim o desenvolvimento da microbiota existente. A dieta nutricional também é considerada um fator essencial para o desenvolvimento da microbiota, quando realizada de forma desbalanceada diminui a nutrição intestinal dificultando o desenvolvimento ou reduzindo a quantidade de bactérias benéficas presentes no intestino. $\mathrm{O}$ uso de antibióticos, antifúngicos e antiparasitários interfere diretamente na quantidade de colônias de microrganismos benéficos existentes. Doenças autoimunes e fatores genéticos sugerem pontos expressivos a serem observados para se analisar a qualidade do desenvolvimento da microbiota (PAIXÃO; CASTRO, 2016).

Cada parte dos intestinos, em estado fisiológico, possui uma população específica de microrganismos. No jejuno, espécies de bactérias do gênero Streptococcus e Lactobacillus são encontradas em maior quantidade, na porção proximal do íleo prevalecem as enterobactérias, e na porção mais distal do íleo e no cólon, prevalecem as Enterococcus fecalis, bifidobacterium sp., Peptococcus sp., Peptostreptococcus sp., Clostridium difficile e Lactobacillus sp. (WOODMANSEY, 2007).

\subsection{A ação de nutrição e proteção metabólica realizada pela microbiota 3.2.1 Ação de Nutrição}

Segundo Oliveira e Batista (2016), a fermentação lática realizada pelas bactérias probióticas no intestino permite o aumento da absorção, em relação a sua taxa básica, de vitaminas do complexo $\mathrm{B}$ em mais de $50 \%$ e de nutrientes como o ácido fólico e vitamina $\mathrm{C}$ em mais de Iоo\%, além de aumentar a digestão de proteínas e gorduras.

A microbiota intestinal possui funções que são de importância vital. Uma microbiota saudável pode impedir a colonização do intestino por microrganismos exógenos com potencial patogênico, assim como promover uma homeostase imunológica possibilitando uma ativação das células do sistema imune, além de fornecer uma 
contribuição nutricional devido aos seus metabólitos, que servem como fontes extras de energia e de vitaminas (STURMER et al., 2012).

As Bifidobacterium sp. e Lactobacillus sp. assumem funções enzimáticas que metabolizam substratos e geram, a partir destes metabólitos essenciais, uma competente nutrição das células do epitélio intestinal. Existem outras espécies de bactérias, como Escherichia coli, cujas cepas comensais desempenham um papel importante no metabolismo da lactose e produção de vitaminas (PAIXÃO; CASTRO, 2016).

As bifidobactérias têm aproximadamente 30 espécies conhecidas, porém, as mais estudadas devido sua relevância clínica são as espécies B. longum (FIGURA 3), B. breve, B. infantis e B. bifidum. Todas essas cinco espécies aparecem presentes, em maior escala, no trato intestinal de crianças. Desempenha um papel nutricional de extrema importância tanto no que se refere à questão celular quanto em caráter sistêmico. Estas bactérias possuem um metabolismo capaz de estimular a absorção e produção de diversas substâncias essenciais tanto às células componentes do trato intestinal, quanto ao organismo humano. Dentre elas vitaminas K, BI (Tiamina), B2 (Riboflavina), B3 (Niacina), B5 (ácido pantotênico) e B6 (Piridoxina) (GORISSEN et al., 2010).

FIGURA 3 - Bifidobacterium longum.

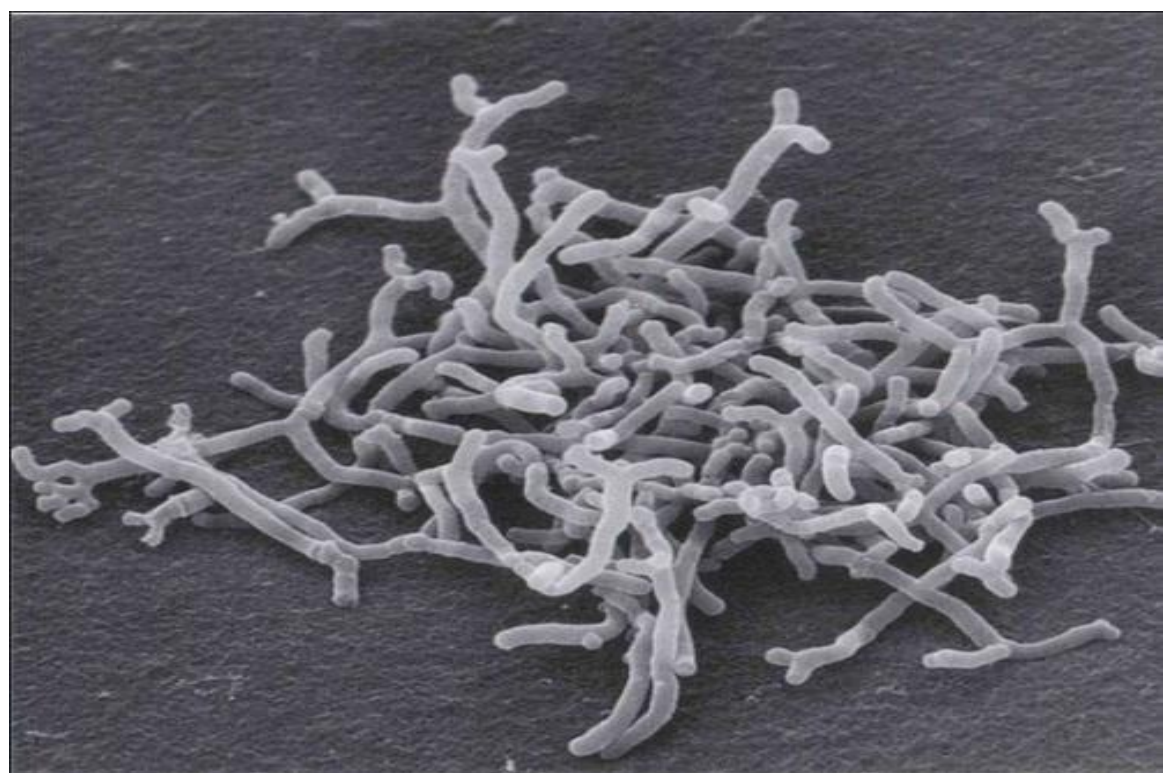

Fonte: https://www.indiamart.com/proddetail/bifidobacterium-longum-19237967948.html 
Além disso possuem a capacidade de produzir ácidos benéficos a partir de carboidratos obtidos na alimentação, como é o caso dos ácidos graxos de cadeia curta, o butirato e propionato, obtidos através do metabolismo do amido, essenciais para a nutrição e regulação funcional dos colonócitos e enterócitos (DE VADDER et al., 2014).

Os lactobacilos são produtores naturais de ácido lático (lactato), que confere à parede intestinal a manutenção do seu $\mathrm{pH}$, mantendo-a com acidez relativamente elevada, entre 5,5 (cinco vírgula cinco) e 5,6 (cinco vírgula seis). Essa correção natural de $\mathrm{pH}$ é de extrema importância para o funcionamento das células intestinais, promovendo um $\mathrm{pH}$ local ótimo. Dentre a grande variedade de espécies de lactobacilos, destacamos as de maior importância clínica: L. casei (FIGURA 4), L. reuteri, L. rhamnosus, L. salivarius e L. acidophilus (CAPOZZI et al., 2012).

FIGURA 4 - Lactobacillus casei.

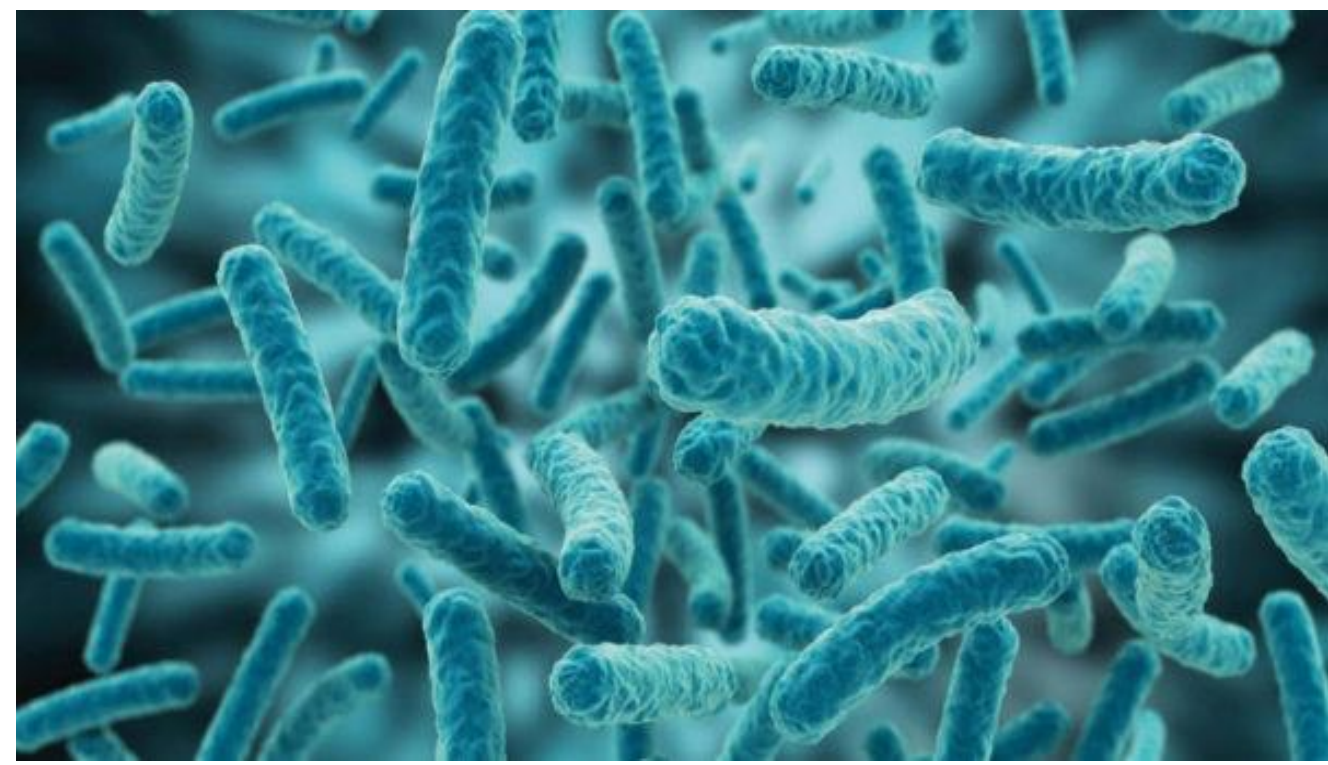

Fonte: http://www.nootroposapiens.com/lactobacillus-casei/

\subsubsection{Ação de Imunomodulação}

Os indivíduos possuem, a princípio, uma capacidade natural de desenvolver um sistema complexo de resposta defensiva contra agentes patológicos que possam vir a afetar o bom funcionamento do organismo. Este sistema de defesa denomina-se sistema imune, e 
as respostas imunológicas realizadas por ele podem ser divididas em duas etapas: a resposta inata, uma resposta ampla que ocorre como sistema primário de defesa, e a resposta adquirida, que tem ações mais específicas. Nos seres humanos, este sistema é ubíquo e muito bem distribuído, porém, a maior parte das ações defensivas do organismo ocorre nos tecidos linfoides associados às mucosas (MALT) (ABBAS; LICHTMAN; PILLAI, 20II).

No GALT, assim como nos demais tecidos, existem diversas células capazes de reconhecer agentes patógenos. Tais células são providas de receptores de reconhecimento de padrões (RRP), proteínas com capacidade de reconhecer padrões moleculares associados a patógenos e promover a ativação da célula de defesa. Células dendrídicas e macrófagos são células, que após realizarem ação de fagocitose dos antígenos, liberam citocinas no meio com a finalidade de mobilizar mais células de defesa para local, e assim, desencadear sua atividade objetiva, a resposta imunológica inata (KIM, 2013).

Os fagócitos, que realizam a atividade imunológica primária (inata), são também responsáveis pela ativação da resposta imunológica secundária (adquirida), sendo esta, realizada pelos linfócitos $\mathrm{T}$ e B. As ativações e diferenciações linfocitárias são moduladas pelo tipo de citocina liberada no tecido, onde cada sinalização quimiotática realizada pelos fagócitos será responsável por um tipo de resposta imune. A resposta adquirida ou adaptativa é dependente de antígenos que serão responsáveis por qual diferenciação o linfócito irá sofrer e qual o tipo de resposta o linfócito dará (RUSS et al, 2013).

De acordo com Lopetuso et al. (2013), a microbiota intestinal em conjunto com o GALT, tem um papel fundamental na imunomodulação. A presença de uma microbiota saudável induz o aumento de secreção de citocinas antinflamatórias, como a interleucina $\operatorname{dez}$ (IL-Io), e o fator transformador de crescimento- $\beta$ (TGF- $\beta$ ), que são indispensáveis na diferenciação dos linfócitos $\mathrm{T}$ em linfócitos $\mathrm{T}$ reguladores ( $\mathrm{T}$-reg) (FIGURA 5). Essa diferenciação celular, juntamente com a elevação da produção de imunoglobulina A (IgA), aumenta a resposta imunológica tolerogênica, diminuindo os efeitos danosos causados pelos processos inflamatórios. 
FIGURA 5 - Diferenciação da T-REG.

\section{Diferenciação de células Treg:}

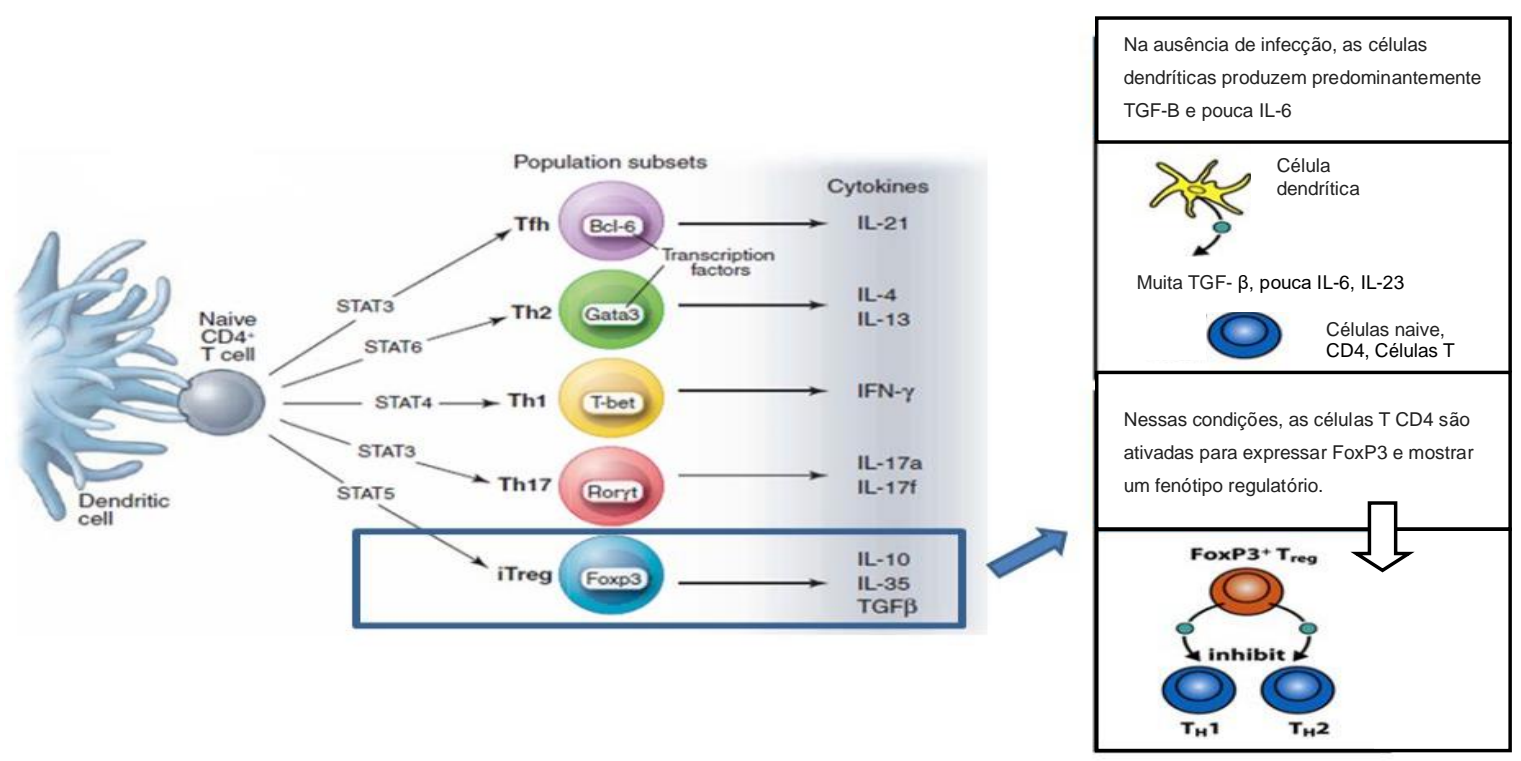

Fonte:https://slideplayer.com.br/slide/4784645/14/images/I6/Diferencia\% $\mathrm{C}_{3} \% \mathrm{~A}_{7} \% \mathrm{C}_{3} \% \mathrm{~A}_{30}+\mathrm{de}+$ c\% $3 \%$ A9lulas+Treg\%3A.jpg

Além da defesa gerada pelas células do sistema imune, as células epiteliais do intestino (colonócitos e enterócitos) funcionam como uma barreira mecânica, no controle da absorção e excreção de água e de nutrientes para o corpo, além de executarem função imunomoduladora por estarem diretamente ligados ao GALT (BARBOSA et al., 20I0).

A microbiota comensal saudável funciona como uma barreira de proteção biomecânica e bioquímica no trato intestinal. A microbiota benéfica está ligada à mucosa do intestino integrada ao GALT, onde age em conjunto com ele, de forma a exercer o reconhecimento dos agentes patogênicos estimulando o tecido a fornecer uma resposta imunológica precisa (JIANG et al., 2016).

Segundo Moens e Veldhoen (2012), a microbiota intestinal, quando preservada, já fornece ao intestino uma proteção contra patógenos oportunistas transitórios existentes no lúmen intestinal, ocupando os sítios de adesão e impedindo os microrganismos patógenos de se instalarem na parede intestinal através da competição por espaço territorial, agindo como uma barreira biomecânica. Além desta disputa, a microbiota comensal compete com 
os patógenos pela captação de nutrientes essenciais, diminuindo a possibilidade da instalação desses microrganismos transitórios.

Outro fator de igual importância é a barreira bioquímica proveniente do metabolismo da microbiota comensal. Os metabólitos produzidos agem como repelentes para os microrganismos patógenos devido à produção de bacteriocinas, toxinas que impedem a proliferação e instalação de outras bactérias patogênicas, à estimulação linfocitária e à produção de anticorpos do tipo IgA no local (OLIVEIRA; BATISTA, 20I6).

As bifidobactérias, por exemplo, desempenham um papel importante no estímulo da produção e migração linfocitária. Naturalmente possuem em sua composição substâncias como o muramil dipeptídeo, que atua como estimulante das células de defesa presentes na mucosa intestinal. Estas células produzem citocinas inflamatórias que atraem mais células de defesa para o tecido, aumentando a resposta imunológica local (GIRARDIN et al., 2003). Além de produzirem substâncias nutritivas para a mucosa e epitélio intestinal, também são produtoras naturais de bacteriocinas (ALMEIDA et al., 2016).

As cepas comensais de E. coli são produtoras naturais de toxinas benéficas, conhecidas como colicinas, que impedem a proliferação e instalação de sua própria espécie de característica patogênica (SWEDSINSKI et al., 200I).

\subsection{Disbiose}

A ação conjunta entre o epitélio intestinal, GALT e a microbiota intestinal, fornece ao ser humano uma ampla rede de proteção primária contra infecções e ação de toxinas. Essa interação funciona como uma corrente, que precisa ter seus elos preservados para que todo o conjunto desempenhe corretamente sua função. A deficiência funcional de qualquer um desses fatores favorecem outros fatores a deixarem de desempenhar seu papel de forma adequada, ocasionando uma sobrecarga laboral nos demais tecidos. Esse processo denominase disbiose (FIGURA 6) (CHAN; ESTAKI; GIBSON, 2013).

A disbiose gera uma significativa deficiência na produção dos ácidos orgânicos com consequente desnutrição das células. Essa deficiência nutritiva leva ao mau funcionamento da mucosa intestinal, tanto na sua permeabilidade (absorção de água e nutrientes), quanto 
no reconhecimento de microrganismos patógenos, promovendo o desenvolvimento de infecções e debilitando as respostas imunológicas (BERDANI; ROSSI, 2009).

Quando há disbiose, as barreiras mecânica, biomecânica e bioquímica presentes na mucosa intestinal ficam debilitadas. Este efeito faz com que a quantidade de células de defesa diminua na mucosa, que a quantidade de sítios de adesão aumente, colaborando com a ocorrência de migração, adesão e colonização por patógenos oportunistas. Após a colonização patogênica e eventual produção de toxinas pelos patógenos, inicia-se uma agressão direta ao epitélio intestinal, possibilitando a passagem de patógenos ativos e destas toxinas para o tecido linfoide. Este, por sua vez, atua utilizando linfócitos de forma improvisada, tendo em vista que a ação primária, que seria exercida pelos fagócitos da mucosa, não foi desempenhada (CHAN;ESTAKI; GIBSON, 2013).

FIGURA 6: Função do sistema Digestório e Disbiose.

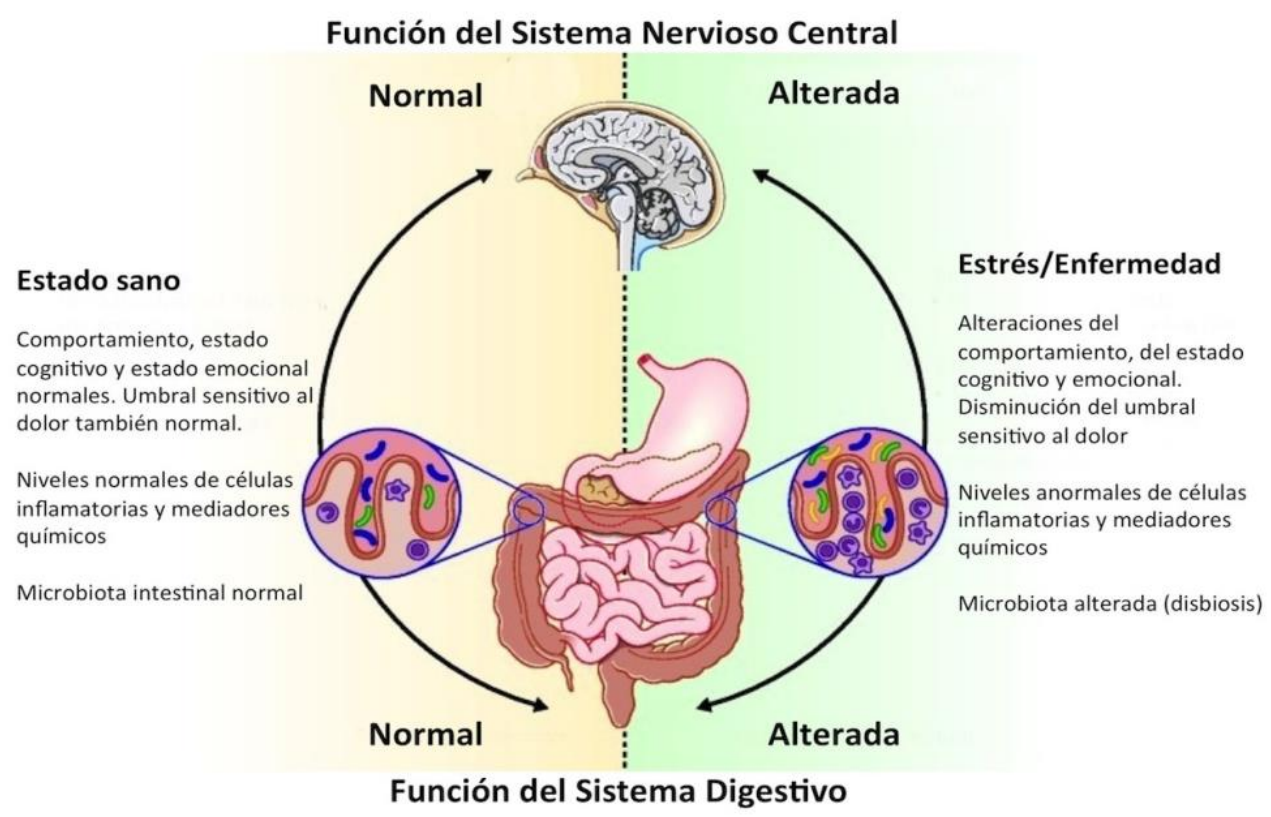

Fonte: http://www.carmides.com/microbiota-intestinal-y-obesidad/

A disbiose proporciona além da deficiência nutritiva às células da parede intestinal, uma deficiência na comunicação entre a mucosa e o tecido linfoide. Esse efeito é o resultado da diminuição na quantidade de células de defesa no local e consequente redução da resposta imune, o que afeta diretamente a parede do intestino, possibilitando a absorção de 
microrganismos ativos e de substâncias fisiologicamente indesejáveis (HAWRELAK; MYERS, 2004).

\subsection{Microrganismos Oportunistas}

No lúmen intestinal transitam diversos microrganismos que praticamente não oferecem risco quando o indivíduo possui uma microbiota equilibrada. Há gêneros e espécies de agentes patógenos, chamados de microrganismos oportunistas, que aproveitam de uma disbiose para colonizar o intestino, causando diversas complicações clínicas reversíveis, mas que podem gerar grandes danos ao indivíduo (CANI et al., 2007).

FIGURA 7 - Colite Pseudomembranosa causada por Clostridium difficile.

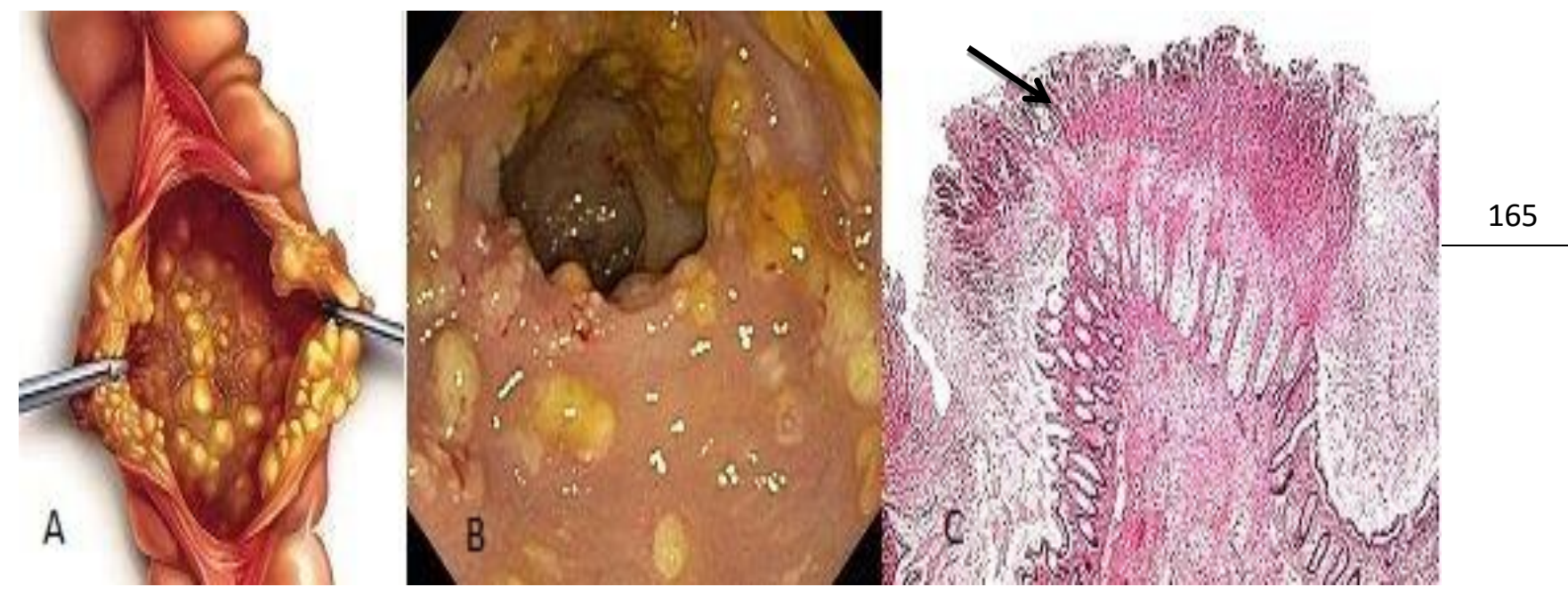

A. Desenho simulando corte na parede do cólon; B. Imagem de colonoscopia indicando presença de pseudomembranas; C. Imagem microscópica de lâmina de tecido epitelial intestinal mostrando acúmulo de pseudomembranas acima das microvilosidades (indicado pela seta). Fonte: adaptado pelos autores. Figuras extraídas na internet. A. pinterest.com; B. treat-simply.com; C. womenhealthguide.net

Clostridium difficile é uma bactéria oportunista que em condições fisiologicamente normais não apresenta risco à saúde do indivíduo, pois a microbiota benéfica tem a responsabilidade de evitar a adesão e colonização do C. difficile à parede do intestino. Após tratamentos com antimicrobianos, principalmente os de amplo espectro, a microbiota comensal diminui sua população, dando espaço para a colonização pela C. difficile. Esta 
bactéria, após sua fixação à parede intestinal, passa a produzir enterotoxinas dos tipos "A" e "B", que são responsáveis, respectivamente, pelo desenvolvimento de diarreias e colites pseudomembranosas (FIGURA 7). As enterotoxinas "A" e "B" interferem na estrutura celular do epitélio intestinal, alterando sua permeabilidade e consequentemente causa diarreia. Em outro cenário, estas toxinas podem formar camadas sobre o epitélio intestinal, conhecidas como pseudomembranas, o que caracteriza a colite pseudomembranosa, que em alguns casos pode ser fatal (GIRY et al., 1995).

A Candida albicans, exemplo de microrganismo oportunista, é uma levedura que também se beneficia das disbioses para colonizar. As leveduras metabolizam os carboidratos provenientes da alimentação através da fermentação alcoólica, convertendo os açúcares em alcoóis e acetaldeídos. Esse processo de fermentação leva à produção de gases, causando vários desconfortos como cólicas intestinais, distensão abdominal e interferência no trânsito intestinal. $\mathrm{O}$ aumento da fermentação alcoólica e o baixo peso molecular desses metabólitos são fatores que possibilitam sua maior absorção pelas células intestinais e, consequentemente, aumentam a concentração alcoólica no sangue, podendo afetar outros órgãos e até interferir na capacidade cognitiva do paciente infectado (GONIA et al., 2015).

\subsection{Uso dos probióticos e prebióticos no reequilíbrio da microbiota}

O organismo possui mecanismo próprio para manutenção do equilíbrio das bactérias intestinais. Porém, quando este mecanismo falha, devido às condições patológicas ou por uso de medicações, os probióticos são indicados para a regulação da função desta microbiota (OLIVEIRA; BATISTA, 2016).

Os probióticos são alimentos constituídos de microrganismos conhecidos, que quando administrados em quantidade adequada, trazem benefícios ao hospedeiro. São microrganismos que trabalham em simbiose com o ser humano, promovendo o reequilíbrio da microbiota afetada. Atualmente são utilizadas bactérias dos gêneros Bifidobacterium sp, Lactobacillu sp (TABELA 2), Bacteroides sp, Enterococcus sp, eubactérias, além de leveduras, porém a combinação ideal para consumo ainda não é conhecida (FLESCH; POZIOMYCK; DAMIM, 2014). 
TABELA 2 - Aplicabilidade dos microrganismos Lactobacillus casei, Lactobacillus rhamnosus, Lactobacillus acidophilus e Bifidobacterium lactis em situações clínicas.

\begin{tabular}{|c|c|}
\hline Cepa & Situação Clínica \\
\hline $\begin{array}{l}\text { Lactobacillus } \\
\text { casei }\end{array}$ & $\begin{array}{l}\text { - Prevenção da diarreia associada a antibióticos em adultos } \\
\text { - Prevenção de diarreia por C. difficile em adultos } \\
\text { - Terapia adjuvante para erradicação de H. pylori } \\
\text { - Complementa o crescimento do Lactobacillus acidophilus } \\
\text { - Auxilia na digestão ereduçãoà intolerância à lactosee constipação }\end{array}$ \\
\hline $\begin{array}{l}\text { Lactobacillus } \\
\text { acidophilus }\end{array}$ & $\begin{array}{l}\text { - Prevenção da enterocolite necrosante em lactente pré- maturo } \\
\text { - Prevenção de diarreia por C. difficile em adultos } \\
\text { - Prevenção da diarreia associada a antibióticos em adultos } \\
\text { - Tratamento da diarreia aguda infecciosa em crianças } \\
\text { - Produz enzima lactase } \\
\text { - Aumenta a imunidade }\end{array}$ \\
\hline $\begin{array}{l}\text { Lactobacillus } \\
\text { rhamnosus }\end{array}$ & $\begin{array}{l}\text { - Tratamento da diarreia aguda infecciosa em crianças } \\
\text { - Prevenção da diarreia associada a antibióticos em crianças } \\
\text { - Prevenção da diarreia associada a antibióticos em adultos } \\
\text { - Prevenção da diarreia nosocomial em crianças } \\
\text { - Terapia adjuvante para erradicação de H. pylori } \\
\text { - Alivia alguns sintomas da síndrome do intestino irritável }\end{array}$ \\
\hline $\begin{array}{l}\text { Bifidobacterium } \\
\text { Lactis }\end{array}$ & $\begin{array}{l}\text { - Prevenção da enterocolite necrosante em lactente pré- maturo } \\
\text { - Prevenção de diarreia por } C \text {. difficile em adultos } \\
\text { - Prevenção e manutenção da remissão na pouchit }\end{array}$ \\
\hline
\end{tabular}

Fonte: (FLESCH; POZIOMYCK; DAMIM, 2014) 
Os probióticos são apresentados em diferentes formas para consumo: tabletes, comprimidos, pós, cápsulas ou composições líquidas e semissólidas (BRASIL, 2002). As formas comerciais mais comuns são as de leite fermentado, iogurtes, pós e cápsulas. Sendo as duas primeiras mais populares no Brasil (OLIVEIRA; BATISTA, 20I6).

Um estudo de Garcia et al. (2016) demonstra as ações benéficas da utilização do fungo Saccharomyces cerevisiae (levedura de cerveja) como probiótico. A levedura demonstrou ter grande eficácia na estimulação da produção de IgA na mucosa intestinal, no aumento da atividade de fagócitos peritoneais e na redução da população de enterobactérias patogênicas.

JIANG et al. (2016) demonstraram em sua pesquisa um aumento significativo de linfócitos T-CD4, T-CD8 e T-Reg, no GALT e a redução da expressão de citocinas inflamatórias após a administração de cepas de lactobacilos.

Ambalam et al. (2016) apontam informações de diversos estudos que evidenciam o desenvolvimento de câncer colorretal e outras doenças crônicas do intestino associadas à disbiose intestinal. Portanto, a modulação da microbiota utilizando probióticos com a finalidade de prevenir essas patologias é prontamente indicada.

A utilização dos probióticos como base profilática, para manter o equilíbrio da microbiota intestinal, além de promover o estímulo ao sistema imunológico, promove também a redução dos níveis da lipoproteína LDL, um aumento significativo dos níveis de lipoproteína HDL, maior eficiência do controle fisiológico da glicemia, o aumento da nutrição dos enterócitos e consequente aumento da permeabilidade funcional da mucosa intestinal (FLESCH; POZIOMYCK; DAMIM, 2014).

Para um melhor aproveitamento profilático dos probióticos é necessária adição de alguns alimentos na dieta, conhecidos como prebióticos, que são substâncias não metabolizadas pelo ser humano devido à falta de algumas enzimas, mas que servem como alimento para os microrganismos que compõem a microbiota e viabilizam o crescimento populacional destes no trato intestinal (PARK; FLOCH, 2007).

Os prebióticos, comumente utilizados, são compostos por polissacarídeos de cadeia curta (oligossacarídeos) e alcoóis de açúcares, que podem ser obtidos de forma natural pela ingestão direta de alguns vegetais como banana, cebola, alho, alcachofra e raízes de chicória 
ou através de extratos prebióticos, obtidos da fermentação alcoólica de alguns polissacarídeos a partir da utilização de bactérias, leveduras ou por ação enzimática. Esses prebióticos atualmente são comercializados em formas solúveis, insolúveis e mistas (FLESCH; POZIOMYCK; DAMIM, 2014).

Os prebióticos com maior importância clínica atualmente são a inulina e outros fruto-oligossacarídeos (FOS), polissacarídeos derivados da frutose. A inulina é geralmente extraída da raiz de chicória e de alguns outros bulbos vegetais como a cebola e o alho. São polissacarídeos não absorvíveis pelos seres humanos, mas que são altamente nutritivos aos componentes da microbiota intestinal, em especial às bifidobactérias (CARABIN; FLAMM, 1999).

Uma variante da administração profilática de probióticos é a conjugada, na qual se administram os probióticos juntamente com os prebióticos. Os alimentos funcionais administrados dessa forma são conhecidos como simbióticos. Estes, por sua vez, já demonstraram ter maior eficácia no tratamento de doenças do trato intestinal e disbioses mais severas, onde tanto a microbiota quanto a nutrição desta, estão comprometidos (FOOD INGREDIENTS BRASIL, 20II).

Um estudo realizado por Rafter et al. (2007) demonstrou que a administração de simbióticos preparados com cepas de Lactobacilus rhamnosus e Bifidobacterium lactis combinadas com inulina e FOS tiveram um excelente resultado quanto à redução da possibilidade do desenvolvimento de câncer colorretal. Este estudo demonstrou alterações significativamente positivas na composição do bolo fecal, evidenciando a diminuição da população de patógenos, como a de Clostridium perfringens no lúmen intestinal e também um aumento na quantidade de bactérias benéficas como as bifidobactérias e lactobacilos.

Os probióticos e simbióticos exercem um papel fundamental na recomposição da microbiota diminuindo a ação de patógenos, toxinas e resíduos potencialmente cancerígenos, além de readaptar a resposta imune comprometida pela microbiota deficiente, aumentar a produção de substâncias nutrientes ao intestino e promover a apoptose de células cujas funções estão comprometidas (BERGMARK; URBINA, 2005).

Outra forma de reposição da microbiota que vem sendo estudada desde a década de I950 é o transplante da microbiota fecal (TMF), que consiste em coletar e processar o 
material fecal de indivíduos saudáveis e introduzi-lo em indivíduos doentes. O TMF pode ser realizado por via oral com o uso de cápsulas, por via endoscópica ou por colonoscopia. $\mathrm{O}$ tipo de administração da microbiota saudável varia de acordo com a condição física do paciente (ZHANG; LUO; SHI, 20I2).

O TMF é aplicado no tratamento de diversas patologias ligadas ao intestino, como a síndrome do intestino irritável, diarreias recorrentes idiopáticas ou mesmo em caso de diarreias relacionadas a infecções (SONG et al., 2013).

O uso do TMF no tratamento de doenças derivadas de infecções bacterianas do trato intestinal, como é o caso da colite pseudomembranosa (CPM) causada pela Clostridium difficile, demonstra que essa modalidade de tratamento é mais eficaz do que os tratamentos convencionais à base apenas de antibióticos (KASSAM et al., 2015).

$\mathrm{O}$ estudo de Ganc et al. (2015) demonstra que cerca de 80\% dos pacientes com diarreias recorrentes derivadas da CPM, que foram tratadas com o TMF, tiveram um resultado clinicamente superior aos resultados obtidos pelos tratamentos antibióticos habituais, pois além dos pacientes terem apresentado melhora em 24 horas, o índice de recorrência da diarreia foi muito menor, relatando apenas um caso de recorrência em 12 pacientes tratados com TMF.

Diversos estudos estão sendo realizados com o objetivo de comprovar que a utilização dos probióticos e prebióticos pode ser muito mais abrangente. Apesar da relação entre a microbiota e os alimentos funcionais já ser discutida há décadas, pesquisas mais recentes evidenciam o tratamento de patologias diversas com aplicabilidade dos simbióticos, inclusive na melhora do condicionamento físico e no desempenho de atletas, além da melhora na qualidade de vida, de quem pretende aumentar ganhos de massa magra ou reduzir níveis elevados de lipoproteína LDL no sangue (RAIZEL et al., 20II).

\section{CONSIDERAÇÕES FINAIS}

O desequilíbrio microbiano compromete o estado fisiológico do epitélio intestinal, aumenta a absorção de substâncias e microrganismos indesejados, podendo causar danos a todos os demais tecidos e órgãos do corpo. A indicação e a administração dos probióticos, prebióticos e simbióticos é cada vez mais utilizada em todo o mundo na recomposição da 
microbiota danificada, tratamento de doenças do trato intestinal e, em especial, na prevenção destas. O uso destes alimentos funcionais, tanto no âmbito ambulatorial quanto hospitalar, apresenta excelentes resultados no tratamento e prevenção de diversas doenças.

Existem algumas combinações já formuladas e conhecidas para os simbióticos que são amplamente utilizadas no tratamento de várias patologias ligadas ao trato intestinal, porém, com a finalidade de conhecer quais seriam as combinações probióticas mais eficazes, ou quais seriam as proporções exatas entre probióticos e prébióticos, os resultados apresentados pelos estudos realizados até a presente data evidenciam um enorme valor terapêutico. Entretanto existe a necessidade de estabelecimento de novos padrões de combinações entre probióticos e prebióticos, com o objetivo de se avaliar novas possibilidades de aplicação ou melhora no balanceamento das composições já existentes.

\section{REFERÊNCIAS BIBLIOGRÁFICAS}

- Função da sistema Digestório (Figura I). Disponível em: 〈http://www.carmides.com/microbiota-intestinal-y-obesidad/〉. Acesso em: 28/10/2018.

Ação das Células $\mathbf{M}$ (Figura 2). Disponível em:
〈https://canalcederj.cecierj.edu.br/recurso/8328>. Acesso em: 28/II/2018.

$$
\text { Bifidobacterium longumm (Figura 3). Disponível em: }
$$
https://www.indiamart.com/proddetail/bifidobacterium-longum-19237967948.html
Lactobacillus
casei
(Figura
4).
Disponível
em:

http://www.nootroposapiens.com/lactobacillus-casei/

Diferenciação da T-Reg (Figura 5). Disponível em: https://slideplayer.com.br/slide/4784645/14/images/16/Diferencia\% ${ }_{3} \% \mathrm{~A}_{7} \% \mathrm{C}_{3} \% \mathrm{~A}_{30}+\mathrm{d}$ e+c\%C3\%Aglulas+Treg\%3A.jpg

- Morfologia do Intestino e Disbiose (Figura 6). Disponível em: $\langle$ https://resumosdemedicina. wordpress.com/2016/o4/II/anatomia-do-sistema-digestorio〉. Acesso em: 28/10/2018.

Colite pseudomembranosa (Figura 7). Figuras extraídas da internet. A. https://br.pinterest.com/pin/500814421045530526/?lp=true> , B. Disponível em $\langle$ http://treat-simply.com/pt/records/6203〉, C. Disponível em 
https://it.womenhealthguide.net/colite-pseudomembranosa-infezione-da-clostridium5567. Acesso em:22/11/2018

ABBAS, A.K.; LICHTMAN, A.H.; PILLAI, S. Imunologia Celular e Molecular. $7^{\underline{a}}$ Ed. Rio de Janeiro: Elsevier Editora, 2011. 592p.

ALMEIDA, L. et al. Disbiose intestinal. Revista Brasileira de Nutrição Clínica. Sao Paulo, v. 24, n. I, p. 58-65,jan. 2009.

AMBALAM, P. et al. Probiotics, prebiotics and colorectal cancer prevention. Best Practice drResearch Clinical Gastroenterology. 30(I): 199-31. Feb, 2016.

ANDRADE, A. Microflora intestinal: uma barreira imunológica desconhecida. 2009/2010. Dissertação (Mestrado Integrado em Medicina) - Instituto de Ciências Biomédicas Abel Salazar na Universidade do Porto, Porto, 2009/2010.

ASHIDA, H. et al. Bacteria and host interactions in the gut epithelial barrier. Nature Chemical Biology; 8 (I): 36-45. Tokio, 2012.

BARBOSA, F. et al. Microbiota indígena do trato gastrintestinal. Revista de Biologia e Ciência da Terra, Aracaju,v. Io, n. I, p. 78-93, jan./jun. 2010.

BENGMARK, S.; URBINA, J. J. O. Simbióticos: una nueva estrategia en el tratamiento de pacientes críticos. Nutrición Hospitalaria, Madrid, v. 20, n. 2, p. 147-156, 2005.

BERDANI, R.; ROSSI, E. Microbiota intestinal e probioticos: implicacoes sobre o cancer de colon. Jornal Português de Gastrenterologia, Lisboa, v. 15, p. 19-28, jan./fev. 2009.

BRASIL. Ministério da Saúde. Substâncias Bioativas e Probióticos, Isolados com Alegação de Propriedades Funcionais e/ou de Saúde. Agência Nacional de Vigilância Sanitária. Resolução RDC no 2, de 07 de janeiro de 2002. São Paulo, ANVISA: 2002.

CANI P.D. et al. Metabolic endotoxemia initiates obesity and insulin resistance. PubMed Diabetes. Toulouse, 2007;56:1761-72.

CAPOZZI V. et al. Lactic acid bacteria producing B-group vitamins: a great potential for functional cereals products. Appl Microbiol Biotechnol. Foggia, 2012. 96:piz83.

CARABIN, I.G.; FLAMM, W.G. Evaluation of safety of inulin and oligofructose as dietary fiber. Regul Toxicol Pharmacol.1999;30:268-82.

CARICILLI A.M. et al. Gut microbiota is a key modulator of insulin resistance in TLR 2 knockout mice. PLoS Biol. São Paulo, 20II;9(I2):eıoor212. 
CARVALHO, EB; SOARES, AG; SOARES, LG. A incorporação dos probióticos na alimentação humana. Revista Digital de Nutrição - Nutrir Gerais, 2012. Disponível em: <https://www.unilestemg.br/nutrirgerais/downloads/artigos/ volume6/edicao-ro/aincorporacao-de-probioticos-na-alimentacao-humana.pdf> Acesso em 25 Out. 2018.

CHAN, Y.K.; ESTAKI, M.; GIBSON, D.L. Clinical Consequences of Diet-Induced Dysbiosis. Ann. Nutr. Metab.; v. 63, suppl. 2, p. 28-40, 2013.

DE VADDER F. et al. Microbiota-generated metabolites promote metabolic benefits via gut-brain neural circuits. Cell. Lyon, 2014; 156(I-2): 84-96.

FLESCH, A.G.T.; POZIOMYCK, A.K.; DAMIN, D.D.C..O uso terapêutico dos simbióticos. ABCD Arquivos Brasileiros de Cirurgia Digestiva. 27(3):206-209. Porto Alegre, 2014.

FOOD INGREDIENTS BRASIL. Probióticos, prebióticos e simbióticos. Revista Food Ingredients Brasil. n. 17, p. 58-65, São Paulo, 20Ir. Disponível em: < http://www.revistafi.com/materias/177.pdf >. Acesso em: 29 Out. 2018.

GANC, A.J._et al. Transplante de microbiota fecal por enteroscopia alta para o tratamento da diarreia causada por Clostridium difficile. Einstein (São Paulo) 2015, vol.13, n.2, pp.338-339. ISSN $1679-4508$.

GARCÍA, Get al. L. Gut-borne Saccharomyces cerevisiae, a promising candidate for the formulation offeed additives, modulates immune system and gut microbiota. Beneficial Microbes.7(5): 659-668, Córdoba, 2016 Nov 30.

GIRARDIN S.E.et al. Nod2 is a general sensor of peptidoglycan through muramyl dipeptide (MDP) detection. J Biol Chem. Paris, 2003; 278:8869-72.

GIRY M. et al. Transient expression of RhoA, B and C GTPases in He La cells potentiates resistance to Clostridium difficile toxins $\mathrm{A}$ and $\mathrm{B}$ but not to Clostridium sordellii lethal toxin. Infection and Immunity 63:4063-4071, Paris, 1995.

GONIA S. et al. Os oligossacarídeos do leite humano inibem a invasão da Candida albicans de células epiteliais intestinais prematuras humanas. Journal of Nutrition, volume 145, edição 9, I de setembro de 2015, páginas 1992-1998, 2015. páginas 1992-1998.

GORISSEN L. et al. Production of conjugated linoleic acid and conjuga-ted linolenic acid isomers by Bifidobacterium species. Appl Microbiol Biotechnol. Melle, 2010;87:2257---66.51 
HAWRELAK, J. A; MYERS, S. P. The Causes of Intestinal Dysbiosis: A Review. Alternative Medicine Review, v. 9, n. 2, p. 180-197, 2004.

JIANG, Y et al. Immunological mechanisms involved in probiotic-mediated protection against Citrobacter rodentium induced colitis. Beneficial Microbes.7(3): 397-407, 2016 Jun.

KASSAM, Z, LEE, CH, YUAN, Y, HUNT RH. Fecal microbiota transplantation for Clostridium difficile infection: systematic review and meta-analysis. Am J Gastroenterol. 2013;108(4):500-8.

KIM, C.H. Host and microbial factors in regulation of $\mathrm{T}$ cells in the intestine. Frontiers in Immunology; 4 (I4I): I-II, 2013.

LEVINSON, Warren. Microbiologia Médica e Imunologia. ıo ed. Porto Alegre. AMGH, 2010.

LOBÃO, NMP de C. O uso de simbióticos como recurso ergogênico para atletas de futebol. Rio de Janeiro: Curso de pós-graduação Lato sensu da VP Consultoria Nutricional da Universidade Cruzeiro do Sul; 2008

LOPETUSO, L.R. et al. Commensal Clostridia: Leading players in the maintenance of gut homeostasis. Gut Pathogens; 5 (23): I-8, 2013.

MOENS, E.; VELDHOEN, M. Epithelial barrier biology: good fences make good neighbours. Immunology; I35 (I): I-8, 2012

MORAIS, M.B.;JACOB, C.M.A.O papel dos probióticos e prebióticos na prática pediátrica.J. Pediatr.(Rio J.), Porto Alegre, v. 82, n. 5, supl.p. Si89-Si97, nov. 2006.

OLIVEIRA, LT; BATISTA, SMM. A atuação dos probióticos na resposta imunológica. Revista Brasileira de Medicina. Moreira Jr Editora. 2016.

PAIXÃO, LA.; CASTRO, FFS. A colonização da microbiota intestinal e sua influência na saúde do hospedeiro. Universitas: Ciências da Saúde, Brasília, v. I4, n. I, p. 85-96, jan./jun. 2016.

PARK, J.; FLOCH, M.H. Prebiotics, probiotics, and dietary fiber in gastrointestinal disease. Gastroenterol Clin. North America, 2007. 36(I): 47-63.

RAFTER, et al. Dietary synbiotics reduce cancer risk factors in polypectomized and colon cancer patients. Am J Clin Nutr. 2007;85(2):488-96. Disponível em: 〈http://www.ajcn.org/cgi/content/abstract/85/2/488〉. Acesso em: Io/II/2018. 
RAIZEL, R. et al. Efeitos do consumo de probióticos, prebióticos e simbióticos para o organismo humano. Revista Ciência \& Saúde, Porto Alegre, v. 4, n. 2, p. 66-74, jul./dez. 201 I RUSS, B.E. et al. T cell-immunity as a tool for studying epigenetic regulation of cellular differentiation. Frontiers in Genetics; 4 (218): I-10, 2013.

SONG, Y. et al. Microbiota dynamics in patientstreated with fecal microbiota transplantation for recurrent Clostridium difficile infection. PloS One. 2013;8(II):I-II

STÜRMER, E.S. et al. A importância dos probióticos na microbiota intestinal humana. Revista Brasileira de Nutrição Clínica. 27 (4): 264-72, Canoas, 2012.

SWEDSINSKI A.et al. Mucosal flora in inflammatory bowel disease.200I PMID II781279: PubMed Gastroenterology. 2002 Jan;122(I):44-54.

VOLMAN, J.J.; RAMAKERS, J.D.; PLAT, J. Dietary modulation of immune system by $\beta$-glucans. Physiology \& Behavior; 94: 276-284, 2008.

WOODMANSEY EJ. Intestinal bacteria and ageing. Jornal Appl Microbiol. 2007;102(5):1178-86.

ZHANG F, LUO W, SHI Y. Should we standardize the I,70o-yearold fecal microbiota transplantation. Am J Gastroenterol 2012; IO7 (II): 1755 